\title{
Uma leitura da relação de Walter Benjamin com o historicismo e com a escrita romanesca de Alfred Döblin
}

\section{An analysis about the Walter Benjamin's relation with the historicism and with the Alfred Döblin's Roman writing}

\section{Luiz Henrique Ernesto Coelho}

Universidade Federal de Minas Gerais (UFMG), Belo Horizonte, Minas Gerais / Brasil coelho.luizhenrique@gmail.com

Resumo: A congruência entre os textos “O romance histórico e nós”, de Alfred Döblin, e "Sobre o conceito de história", de Walter Benjamin, encontra-se na análise historicista, inserida em uma concepção vanguardista tanto no sentido sociocultural abordado por Benjamin quanto naquele delimitado mais especificamente por uma teoria sobre o gênero do romance, observado no texto de Döblin. Benjamin analisa os fenômenos históricos posicionando-se em relação à corrente historicista, criticando-a e se voltando sempre para uma visão vanguardista, inclusive no tocante à sua escrita. No texto sobre a crise do romance, parte de considerações sobre questões teóricas de autoria de Döblin e analisa a escrita desse autor em Berlin Alexanderplatz, reverenciando tanto a escrita quanto os aspectos teorizantes apontados por ele. Nesse ponto, encontra-se uma flagrante aproximação entre os dois autores como em outros textos de Benjamin e, também, nas proposições encontradas no texto de Döblin acerca do romance histórico. Na presente pesquisa, pretendeu-se analisar os pontos de aproximação entre os textos benjaminiano e dobliniano, bem como os seus distanciamentos, com a finalidade de se propor uma perspectiva que contemple também a escrita de ambos - amparada pela estética modernista - a partir de um viés histórico-teórico.

Palavras-chave: Alfred Döblin; Walter Benjamin; romance histórico; conceito de história.

Abstract: The congruence between the texts "Der historische Roman und wir" (The
historical Roman and us) by Alfred Döblin and "On the concept of history" by Walter
Benjamin concerns the historicist analysis, on a modernist conception both in a social-
cultural sense, intended by Benjamin, and on that one defined more specifically by a 
theory about the Roman, observed in Döblin's text. Benjamin analyses the historical phenomenon relating himself with the historicist stream, criticising it and placing himself in an avant-gardist point of view, including his writing on it. On the text about the Roman crisis, he begins with considerations about theoretical points from Döblin's authorship and analyses this author's writing on Berlin Alexanderplatz, reverencing both the writing method and the theoretical aspects pointed by Döblin. In this way, it is possible to find a flagrant approach between Benjamin and Döblin an, also, on the propositions found on Döblin's text about the historical Roman. On the present article, it was intended to analyse the approaching points between the texts by Benjamin and Döblin, as well as their differences, with the finality to propose a perspective which contemplates also their writings - supported by the modernist aesthetics - from a theoretical historical bias.

Keywords: Alfred Doblin; Walter Benjamin; historical roman; concept of history.

\section{0 historicismo em Benjamin e o romance histórico segundo Döblin}

A forma utilizada por Walter Benjamin para a composição de sua escrita, ou aquilo que o próprio autor define como "representação de ideias", 1 ocorre pela fragmentação do texto em pequenas partes, portadoras, entretanto, de grande densidade. Manuel Ricardo de Lima, em posfácio inscrito no História da literatura e ciência da literatura, compara a escrita de Benjamin, ou melhor, suas "escolhas", a "práticas livres e menos burocráticas, nada estratégicas" (LIMA, 2016, p. 44), já que seu texto não preza por um elemento conclusivo, ao contrário, seus argumentos propõem uma dissonância conceitual - ao que Lima se refere

\footnotetext{
${ }^{1}$ OTTE, 2015, p. 60. "Für die wahre Kontemplation dagegen verbindet sich die Abkehr vom deduktiven Verfahren mit einem immer weiter ausholenden, immer inbrünstigen Zurückgreifen auf die Phänomene, die niemals in Gefahr geraten, Gegenstände eines trüben Staunes zu bleiben, solange ihre Darstellung zugleich die der Ideen und darin erst ihr Einzelnes gerettet ist." (BENJAMIN, 2013, p. 27) [Na verdadeira contemplação, ao contrário, o abandono dos processos dedutivos se associa com um permanente retorno aos fenômenos, cada vez mais abrangente e mais intenso, graças ao qual eles em nenhum momento correm o risco de permanecer meros objetos de um assombro difuso, contanto que sua representação seja ao mesmo tempo a das idéias, pois com isso eles se salvam em sua particularidade." (1984, p.67). Para Theodor Adorno, a "representação" entendida por Benjamin seria muito mais uma "enumeração de fatos." (BRODERSEN, Momme. Spinne im eigenem Netz. Walter Benjamin - Leben und Werk. Bühl-Moos, Elster-Verlag. 1990, p. 212 apud OTTE, 2015, p. 61). Tradução minha.
} 
como a sugestão de uma "constituição abissal do paradoxo", apontado por Benjamin como "imagem dialética". (LIMA, 2016, p. 44)

A dificuldade de entendimento do texto está na sua forma, que se remete à prosa, distanciando-se de uma escrita acadêmica tradicional. Segundo Benjamin, na fala, o locutor desenvolve o texto a partir de períodos individuais, alinhados em um fluxo de pensamentos, muitas vezes absorto e livre, "como quem esboça, com um só traço, um desenho tosco”. Já na escrita, é necessário, a cada sentença, parar e recomeçar. (BENJAMIN, 2013, p. 11) Georg Otte, no seu texto sobre a relação de Benjamin com a escrita (2015), lembra a definição adorniana para tal escrita, sugerindo, não somente no texto intitulado "Parataxis" ADORNO apud OTTE, 2015, p. 63. Tradução minha), de 1963, mas também no anterior "Essay als Form", ${ }^{2}$ a "negação" (Verweigerung) como valor do gênero ensaio, salientado por Benjamin. Segundo Otte,

Adorno assume também, nas "Questões introdutórias de crítica do conhecimento" [Erkenntniskritische Vorrede], o "silêncio" presente nos "conceitos" [Begriffe], rumos [Wendungen], assim como o "contexto dedutivo sem lacunas" [lückenlosen Deduktionszusammenhang], o qual o ensaio nega, pois permite apenas que a totalidade seja privilegiada. ${ }^{3}$

Otte apresenta outras características do texto benjaminiano, relacionadas com as dificuldades de leitura do mesmo. Dentre elas, está o papel mediador dos conceitos. Para Benjamin, esse traço tornaria um conceito apropriado a um fenômeno como parte essencial à ideia, algo em comum com a tarefa da filosofia, para a representação das mesmas. Assim, a "redenção do fenômeno por meio das ideias se efetua ao mesmo tempo que a representação das ideias por meio da empiria". (BENJAMIN, 1984, p. 56-57) O exercício do leitor se encontra naquilo que o autor define para a representação das ideias; estas permanecem indistintas até a aproximação dos fenômenos. Para que ocorra o seu reconhecimento, é preciso que os fenômenos sejam selecionados pelos conceitos e a

\footnotetext{
${ }^{2}$ ADORNO, Theodor W. Der Essay als Form. In: TIEDEMANN, Rolf (Ed.). Noten zur Literatur. Frankfurt/M., Suhrkamp, 1981, 9-33; ADORNO, p. 15-54 apud OTTE, 2015, p. 63. Tradução minha.

${ }^{3}$ ADORNO, Theodor. "Der Essay als Form". In: TIEDMANN, Rolf (Ed.) Noten zur Literatur. Frankfurt/M. Suhrkamp, 1981, p. 9-33 apud OTTE, 2015, p. 63. Tradução minha.
} 
realização de tal seleção proporcione, por força da alteração intelectual, uma divisão tão mais significante, que possibilite tanto a representação das ideias prevista quanto a manutenção dos fenômenos.

É importante ressaltar a análise de Benjamin acerca das vanguardas e como ele se aproxima delas, em sua escrita. Tal aproximação, juntamente com os pontos tratados até aqui, permite a compreensão formal proposta, cuja identificação com o ambiente literário da época é imediata. Tal identificação pode ser esclarecida, inicialmente, pela proposição de uma "descoberta tardia" - certamente historicista - (BENJAMIN, 2013, p. 42. Tradução minha) do barroco literário na Alemanha já no séc. XVIII. Desse modo, ocorre uma descaracterização das suas propriedades temáticas, dada a aproximação com aquelas percebidas no período clássico, presente nas cortes alemãs. Segundo Herbert Cysarz,

A atitude não-polêmica é uma forte característica do Barroco em seu conjunto. Cada autor procura dar a impressão, por tanto tempo quanto possível, mesmo quando segue suas próprias inclinações, de que está seguindo as pegadas de mestres respeitados e de autoridades consagradas. (Cysarz 1, cit., p. 72 apud BENJAMIN, 2013, p. 42; BENJAMIN, 1984, p. 82-83)

As duas escolas - barroca e clássica - operam conjuntamente, pois a dramaturgia aristotélica já se torna uma referência no período, relacionada às teses da forma renascentista do Drama Alemão do séc. XVII. A partir da retomada das definições aristotélicas é percebido o retorno do valor dado ao Drama. (BENJAMIN, 2013, p. 43-44. Tradução minha)

O poeta Andreas Gryphius é, nesse momento, considerado a grande referência literária e sua escrita refere-se a uma temática historicista. Benjamin explica que, no séc. XVII o termo "drama" era utilizado tanto como obra literária, quanto como acontecimento histórico. Até do ponto de vista estilístico, é flagrante o quão próximas as duas acepções se encontram na recepção contemporânea. Bernhard Erdmannsdorffer (1892) reforça o dado historicista apontando para as descrições de guerra, observando, contundo, o "tom de lamentação lamuriosa" dos textos da época. ${ }^{4}$

\footnotetext{
${ }^{4}$ ERDMANNSDORFFER, Bernhard. Deutsche Geschichte von Westfalischen Frieden bis zum Regierungsantritt Friedrich's des Grossen. 1648-1740. v. 1. Berlin 1892 (Allg. Geschichte in Einzeldarstellungen. 3. 7.) p. 102 apud BENJAMIN, 2013, p. 47-48; BENJAMIN, 1984, p. 87-88.
} 
Tanto as características formais quanto aquelas que denunciam uma intenção historicista no texto benjaminiano possibilitam um entendimento mais apurado acerca de suas teses sobre a história. As dezoito teses e dois apêndices se voltam para uma escrita envolvida por nuances prosaicas e que se detém nas questões históricas relativas ao mundo moderno. Jeanne Marie Gagnebin apresenta a relação de tais questões com o texto de Benjamin a partir da "dissolução", da "disseminação" e da "dispersão" (GAGNEBIN, 2013, p. 95) como figuras históricas determinantes do período e, portanto, definidoras de uma relação, estabelecida no lugar entre uma impossibilidade de resistência e a linguagem e a mesma impossibilidade política. Segundo Gagnebin,

[...] a fragmentação moderna, mesmo "pós-moderna" não é unicamente a consequência de um processo de "desencanto" ou de desagregação social. Quer seja como complacência, crueldade ou sobriedade, ela expõe à luz do dia esta força centrífuga inscrita na nossa linguagem e na nossa história. Se a linguagem só torna presente quando diz, justamente, o objeto ausente e a distância que dele nos separa, podemos sem dúvida, sonhar com palavras transparentes e imediatas, com uma prosa "liberada" como a chama Benjamin, mas só continuamos falando e inventando outras frases porque essas palavras "verdadeiras", que nos atormentam, se nos esquivam. (GAGNEBIN, 2013, p. 95)

Em confluência com a atenção destinada às questões da vanguarda literária está a perspectiva döbliniana, que se delimita pela tentativa de estruturar o romance histórico a partir de suas aproximações ou distanciamentos com o romance moderno.

Alfred Döblin inicia seu texto "O romance histórico e nós" (1989) definindo a relação entre autor e leitor e afirmando objetivamente que o romance - ou o exemplo apresentado - está no âmbito da invenção. Certamente, é possível entender tais disposições como uma tentativa de estabelecer, ou melhor, reconhecer a relação como um pacto-ficcional. Isto ocorre no momento em que o leitor aceita que os dados apresentados não fazem parte da realidade, mas de uma realidade possível.

Para o autor existe o "romance ficcional comum", que é algo como uma reminiscência de uma forma de narrar fatos que realmente aconteceram e no qual "não é possível acrescentar algo completamente improvável, um jogo cem por cento irreal [...]” (DÖBLIN, 1989, p. 160161). Esse romance é oriundo da épica, a qual constituía um relato mais 
fiel à real ocorrência dos fatos. Em um momento em que ainda não havia escrita a transmissão era exclusivamente oral, fazia-se comum o acréscimo de elementos "fabulosos". A fixação da informação acontecia através de versos, no intuito de propiciar a repetição e manutenção do conteúdo, muito mais do que uma opção estética. Segundo Döblin,

[...] cabe ao autor hodierno uma dupla tarefa: primeiro, oferecer realidade reconhecível e convincente, mesmo que não transitória - e geograficamente definida - e segundo, fazer com estes recortes da realidade alguma coisa que, no todo, venha a constituir o romance. [...] Através de um acordo secreto, autor e ouvinte sentam-se frente a frente e o autor começa a satisfazer o desejo do ouvinte, apresentando-lhe, para tanto, fatos do mundo, importantes e interessantes, mas muitíssimo comuns, e, de forma alguma, assim como teriam ocorrido de verdade em algum lugar, mas de forma a agradar o ouvinte. (DÖBLIN, 1989, p. 161)

Essa nova tarefa do autor se distancia da premissa da épica: a perspectiva de narração para além dos fatos, de elementos pertencentes a uma tradição, elementos universais. Todavia, aquilo que Döblin chama de fatos "comuns" estabelece uma ponte com a tradição, não somente pela transmissão dos acontecimentos, mas pela característica oriunda da oralidade presente na épica, que emana do romance, sendo, segundo o autor, uma vontade de se "ressaltar, forjar coisas universais". Ainda, o romance recebe, também, o desígnio, por participar no presente de uma formação ideal e universal. (DÖBLIN, 1989, p, 164-165),

Ao apresentar o romance histórico, Döblin lembra que, para além da verossimilhança - esta necessária, também ao que ele chama de "romance comum" - o romance acrescenta dados e personagens históricos. Para o autor isso se relaciona à épica antiga, no que se refere aos acontecimentos reais e, principalmente, aqueles de maior impacto. Essa função, preservada no romance, permite a exposição, fixação e manutenção da memória de tais acontecimentos diante das massas, da "coletividade". Existe, no entanto, a ressalva em relação ao romance histórico, que resguarda o gênero da perspectiva da historiografia. Para Döblin, “[...] não existe distinção fundamental entre um romance comum e um romance histórico. O romance histórico é, em primeiro lugar, um romance; em segundo lugar não é história." (DÖBLIN, 1989, p. 167).

É possível vislumbrar o interesse do leitor relacionado à historiografia. Ele procura os fatos e, diferentemente do romance, abstém- 
se do autor. Segundo Döblin, o leitor aceita, no máximo, uma discussão paralela acerca dos fatos históricos. Renuncia-se à arte em favor da «verdade das coisas históricas». E, caso contrário, se se admitisse a arte, opondo assim o fato e ela, o romance histórico seria um ponto intermediário injustificável. No entanto, a historiografia, mesmo em seu ensejo de buscar uma isenção ao narrar os acontecimentos, fundamenta-se na análise do historiador, o que implica as escolhas deste, no tocante à sua época, classe social, etc. (DÖBLIN,1989, p. 168-170). O historiador, para Döblin,

não conhece, na maioria das vezes, o seu intento ou não o admite; o romancista conhece-o. O historiador, se não for apenas simplesmente cronologista, quer evocar o quadro de uma realidade transcorrida; o romancista também, embora um quadro menor, porém mais concreto e mais inteiro. [...] Dito grosso modo, o historiador revolve o material, procura, está preso e tem a consciência pesada. Afinal, está perseguindo um louco ideal de verdade, um louco ideal de objetividade, que contradiz todas as suas divisões e concepções básicas. O romancista não se ilude, nem a si, nem a nós; o historiador deixará crescer uma barba branca e anunciará: a história universal é julgamento universal. (DÖBLIN, 1989, p. 171)

Walter Benjamin, em suas teses sobre a história (2012), observa as relações historicistas não exatamente sob o prisma literário. Sua perspectiva apresenta um encontro com a visão dobliniana, já que recupera a noção de verdade, pretendida pelo historiador e contextualizada por Döblin. Benjamin analisa, a partir das teses, a desconstrução dos conceitos relativos à historiografia presenciada no modernismo. Posto isso, é possível perceber a aproximação entre os dois autores também pela concepção conjunta de que o ideal historicista seja falho. O que Döblin define como um julgamento universal é percebido, por exemplo, nas reflexões benjaminianas acerca do passado ou, na imagem - modernistado passado. Para além dessa via, Benjamin inscreve as doutrinas liberais, a partir do conceito de "materialismo histórico". Este destrói a concepção de história formulada por Gottfried Keller, ${ }^{5}$ própria do historicismo; para

\footnotetext{
${ }^{5}$ Gottfried Keller (1819-1890): romancista e poeta suíço, geralmente incluído no chamado "realismo burguês", mas mais crítico do que os seus pares alemães e austríacos, influenciado pelo materialismo filosófico de Feuerbach e pelo ideário liberal. (BENJAMIN, 2012, p. 11)
} 
o "Materialismo Histórico", todas as imagens do passado que conflitam com a própria existência do presente - aqui, uma construção modernista - não preservada em tais imagens, deve ser abandonada. (BENJAMIN, 2012, p. 11). Partindo da construção sobre a história, que prevê que o lugar desta é menos um fluxo temporal homogêneo, mas por um tempo preenchido pelo "Agora" (Jetztzeit) (2012, p. 18), encontra-se, no texto de Benjamin, uma definição do ofício do historiador que coincide com aquela dobliniana, já apresentada aqui. Claramente, é possível relacionar o texto de Döblin, ou aquilo que ele entende como "cronologismo" com o que Benjamin aponta como uma limitação do historicismo. Tal limitação é percebida na tentativa simplista de se conectar um fato a outro, sobretudo se um for causa do outro. Isso não faz do fato um fato histórico. Tal transformação ocorre através da perspectiva do historiador, cujo objeto pode estar distante cronologicamente de si. Segundo Benjamin:

O historiador que partir dessa ideia [sobre a relação entre os fatos] desfia os acontecimentos pelos dedos como um rosário. Apreende a constelação em que a sua própria época se insere, relacionando-se com uma determinada época anterior. Com isso, ele fundamenta um conceito de presente como "Agora" (Jetztzeit), um tempo no qual se incrustaram estilhaços do messiânico. (BENJAMIN, 2012, p. 20)

Para Jeanne Marie Gagnebin, O conceito de "Jetztzeit" (agora) de Benjamin, para além da proposição atribuída ao historiador, dado pela relação entre o presente deste e um passado muitas vezes distante, possibilita o surgimento ou o trânsito do passado no presente. Numa perspectiva vanguardista, Manuel Levinas estabelece essa noção de origem (Ursprung), 6 “[...] evento do instante, daquilo que começa a ser... que deve, pelo seu começo, nascer a si, advir a si, sem partir de lugar nenhum".7

Louis Dimier, historiador francês que viveu entre 1865 e 1943, define o papel do historicismo ou as características que circundam o trabalho do historiador. Para ele, tal tarefa concentra-se na coleta dos fatos e a investigação advinda desta, algo que se insinua para o leitor atraindo-o. Antes, "[...] ]os testemunhos [acerca dos fatos] levam a que

\footnotetext{
" Gagnebin opta pela tradução de Ursprung por "surgimento", no entanto, a palavra "origem" parece compreender melhor a colocação de Levinas.

${ }^{7}$ LEVINAS, Emmanuel. De l'existence à l'existant. Paris: Ed. Fontaine, 1947, p. 130131 apud GAGNEBIN, 2013, p. 97.
} 
não se possa pôr em dúvida a coisa, é o seu encadeamento natural que alimenta a sua persuasão... Daí resulta que os fatos se mantêm inteiros, intactos [...]" (DIMIER, 1939, p. 46-47 apud BENJAMIN, 2012, p. 175). $\mathrm{Na}$ carta, onde se insere o referido por Dimier, Benjamin considera essas características como aquilo que ele chama de a "arte do historiador", que se encerra na preservação dos fatos e, mencionando Fustel de Coulanges, pode ser denominada de a "castidade da história". A seguir, na carta, Benjamin aproxima tal preservação a um testemunho equivalente àqueles presentes no Velho e no Novo Testamento, dados os milagres narrados. Esses milagres são defendidos com muitos sofismas e o forte positivismo desses testemunhos torna-os superficiais (BENJAMIN, 2012, p. 176). Posto isso, torna-se relevante a colocação de Gagnebin acerca do teor teocrático, ou messiânico, da história, a qual salva o passado e o presente no presente e realiza a dinâmica relacionada à origem, urdida anteriormente. "[...] [A] história que se lembra do passado também é sempre escrita no presente e para o presente." Assim é estabelecido o "instante", que bem simboliza a vanguarda: a partir da intensidade da renovação, ou, nas palavras de Levinas, no "nascer de si, no advir de si, sem partir de lugar nenhum." (GAGNEBIN, 2013, p. 97) Segundo a autora, tal intensidade, que se opõe à limitação do historicismo, noção apresentada por Benjamin, implicando a tentativa de separação de um fato de outro, se faz

[...] a uma só vez destruidora e salvadora, que faz ruir a ordem, das palavras e das coisas - porque, se algo puder ser salvo, só o será sobre essas ruínas. Violência certamente que esta força que Benjamin chama, justamente, de "messiânica", para marcar também que somente o "Messias" é senhor dela; ela nos é dada parcimoniosamente para respondermos ao apelo do passado no presente, mas a redenção não nos pertence. A famosa "fraca força messiânica" que cabe a cada geração significaria, portanto, mais que nossa lamentável impotência, como sempre se interpreta; ela poderia igualmente assinalar, como o faz esta "suave aproximação" do Reino de que fala o "Fragmento Teológico-político", que somente nossa fraqueza é messiânica, que é em nossas hesitações, em nossas dúvidas, em nossos desvios, que pode ainda se insinuar o apelo messiânico, ali, enfim, onde renunciamos a tudo sem preencher para deixar que algo de outro possa dizer-se. Violência, portanto, mas violência que não podemos usar segundo o nosso bem-querer, pois ela ameaça, justamente, o querer e a soberania da intenção, sua ambição de previsões sem falhas. (GAGNEBIN, 2013, p. 97-98) 


\section{A narrativa e a história da literatura}

Gagnebin, acerca da escrita benjaminiana da história - fragmentada, onde o fato deixa de ser presumivelmente um fato histórico -, questiona a possibilidade de existência dessa escrita, a partir de uma "tradição esburacada" e na qual se faz presente um nexo descontínuo. Tal dilema é percebido por Stephane Mosès, na objeção de Benjamin contra o historicismo, e também na tentativa de elaboração de uma "tradição" dos oprimidos, que, segundo Mosès, vai na direção contrária à da historiografia marxista, pois, na concepção de Benjamin, ela aproxima-se de uma construção acerca da história mal-fadada do proletariado, em suas tentativas suprimidas de revolução, em uma "epopéia vitoriosa". ${ }^{8}$ Gagnebin ainda menciona o intento paradoxal de Benjamin entre o uso da parataxis analisada aqui, a partir de Georg Otte (2015) -, ou seja, a justaposição de palavras e frases, compondo um "fluxo infinito da Erinnerung [lembrança] e da Universalgeschichte" [história universal] e a construção de "um falar abrupto que arrisca sua própria decomposição" (GAGNEBIN, 2013, p. 99).

Em seu texto História da literatura e ciência da literatura (2016), Benjamin procura estabelecer uma ponte entre seu pensamento historicista e uma relação entre este e a história da literatura. Para ele, a história da literatura não se resume a uma disciplina, no sentido de se agrupar acontecimentos, cronologicamente, no âmbito literário. Muito mais, a História da Literatura deve ser percebida como um fenômeno dentro da História Geral. Ele ainda questiona: "Mas será realmente uma disciplina?" (BENJAMIN, 2016, p. 13). O autor, num primeiro momento, se furta a expor o questionamento acerca da relação entre os dois campos, dada a dificuldade de localização da História da Literatura na História e na relação entre ambas. Mesmo entre historiadores como Michael Bernays, Richard Heinzel e Richard Maria Werner surge um impulso no sentido de se compreender tal relação, posição que Benjamin entende como uma "perplexidade epistemológica". A disposição que modifica o entendimento dessas relações, se dá na

renúncia à História, para permutá-la com base nas Ciências Naturais. Se, anteriormente, mesmo compilações bibliográficas revelavam uma ideia do discurso geral, retornavam-se agora obstinadamente trabalhos isolados, o compilar e o conservar (BENJAMIN, 2016, p. 15).

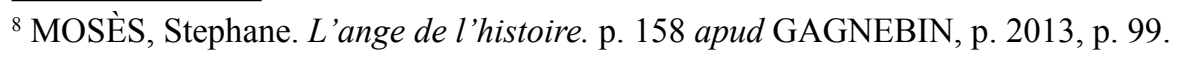


A História da Literatura, para o autor, perde sua tarefa no tocante ao seu caráter científico, algo que está relacionado, certamente, com o momento do declínio da formação intelectual, ocorrido no modernismo. Para Benjamin,

[é] o quanto basta no tocante às circunstâncias sociais. Assim como o Modernismo nivelava, aqui, a tensão entre conhecimento e praxis no conceito museológico de formação intelectual, o mesmo ocorria, no domínio histórico, com a tensão entre o presente e o passado, isto é, entre Crítica e História da Literatura. A História Literária do Modernismo não pensa em legitimar-se, antes de seu tempo, por meio de uma fecunda interpretação do passado, crendo lograr fazê-lo melhor, perante as Letras contemporâneas, através do mecenato. (BENJAMIN, 2016, p. 29)

É justamente aqui que Benjamin se aproxima das considerações sobre o romance Berlin Alexanderplatz quando opõe a escrita épica, que mais se assemelha à do romance de Alfred Döblin, e a escrita romanesca comum. $\mathrm{O}$ gênero do romance se parece, sim, com a epopeia. $\mathrm{O}$ poeta épico, em uma metáfora sobre o mar (BENJAMIN, 1987, p. 54), simplesmente observa aquilo que está em seu entorno. Já o romancista quer percorrer o mar e busca por objetivos, mas sem que haja algum específico. A narrativa épica expõe um sentido sumariamente edificante, no qual "o povo" e seu trabalho estão unidos, algo que remete a um destino previsível e sólido, enquanto no romance, o autor descreve o indivíduo como o "mudo", o "solitário". Melita Gerhard," em sua definição do Romance de Desenvolvimento Alemão, descreve esse gênero como sendo todas as obras em que o problema de inconformidade própria com o mundo, seus progressivos ciclos e amadurecimento em confronto com o mundo e o desejo de querer criar novos caminhos, premissas e objetivos dentro desse mundo. Do mesmo modo, o personagem surgido no romance não é mais capaz de expor suas preocupações, é alguém cujo aprendizado é ineficiente, tanto no sentido de sua apreensão quanto no de sua difusão. Para Benjamin, aquilo que diferencia o romance da forma épica é que ele não se inscreve na tradição oral, como contos de fadas, sagas ou provérbios. (1987, p. 54-55) Ao remeter às relações de Döblin com as formas do romance e a épica, Benjamin relata:

\footnotetext{
${ }^{9}$ GERHARD, Melita. Der deutsche Entwicklungsroman bis zu Goethes "Wilhelm Meister". Halle, 1926 apud JACOBS, 1972, p. 13.
} 
Não quero me alongar-me na tese de que considero útil liberar do livro o elemento épico...útil sobretudo no que diz respeito à linguagem. O livro é a morte das linguagens autênticas. O poeta épico que se limita a escrever não dispõe das forças linguísticas mais importantes e mais construtivas" (BENJAMIN, 1987, p. 55)

Essa referência direta à palestra de Döblin soma-se à reflexão benjaminiana sobre a história ou o historicismo. A chamada "crise do romance" apontada por Döblin expõe o lugar do gênero em meio à tradição, revisa a importância de uma escrita na forma Épica no Modernismo, percebida a partir da admiração de Benjamin, exposta claramente no seu texto sobre Berlin Alexanderplatz. Nelas, Benjamin compara Döblin a André Gide, porquanto os dois autores conseguem definir os espaços, tanto do romance chamado "comum" (por Döblin) quanto daquele histórico e, também a Épica, nas primeiras décadas do século XX.

\section{Considerações finais}

Walter Benjamin e Alfred Döblin postularam suas ideias sobre o lugar do gênero do romance sempre observando a partir do prisma historicista. Tal perspectiva aponta para uma preocupação de ambos não somente com o entendimento e delimitação de conceitos históricos, mas também com a relação desta para com a história da literatura, algo que perpassa elementos estéticos caros ao momento em que ambos os autores vivenciavam o exílio, na França. Tais elementos se fazem mais perceptíveis na escrita benjaminiana, a qual possui grande liberdade, se diferenciando da escrita acadêmica de então. Essa característica aponta para os valores modernistas e que tornam a escrita benjaminiana um objeto de difícil definição, por suas características ensaísticas e prosaicas. A preocupação historicista se inscreve certamente, ou mais diretamente, no texto de Benjamin sobre o tema, mas, também, na análise de Döblin, que delimita os gêneros romanescos transversais ao romance histórico.

A proposta de localização abriga a construção de uma escrita teorizante, sobretudo por parte de Benjamin, que tem a sua forma naquilo que Manuel Ricardo de Lima e Anne Marie Gagnebin muito bem descrevem, como uma escrita "prosaica", "fragmentada" e, ainda, advinda de práticas "sem muita estratégia" ou composta, lembrando Georg Otte, por um encadeamento livre de palavras, compreendido na definição adorniana de parataxis. 
Posto isso, fica claro o intuito de ambos de no ambiente modernista, o romance, a épica e, também o romance histórico. Nesse ponto, Benjamin utiliza objetivamente o contexto dobliniano, que constitui ideia de "crise" do gênero, para compor sua análise da situação dessas formas no período modernista. Ele opõe a épica e o romance, a partir das funções exercidas pelo indivíduo tanto em uma quanto na outra. De fato, naquilo que se refere à épica, ele utiliza a palavra "povo" em detrimento de "indivíduo". Nessa oposição encontra-se uma visão, provavelmente, mais otimista em relação ao romance, mas, mais importante, está a inclusão do romance Berlin Alexanderplatz em sua análise, já que este apresenta uma antítese à tradicional noção de formação, bem estabelecida na história do romance alemão, correspondendo, assim, à descrição de Benjamin, que prevê o indivíduo do romance moderno, entre outras características, como "incapaz de dar ou receber conselhos".

\section{Referências}

ADORNO, Theodor. Essay als Form. In: Deutsche Essays. Prosa aus zwei Jahrhunderten in 6 Bänden. 1972. p. 61-83. Disponível em: $<$ https:// onedrive.live.com/?cid=A43B081EC2D58F79\&id=A43B081EC2D58 $\mathrm{F} 79 \% 21176851 \&$ parId=A43B081EC2D58F79\%213486\&o=OneUp $>$. Acesso em: 30 mai. 2018.

ADORNO, Theodor W. Der Essay als Form. In: TIEDEMANN, Rolf (Ed.). Noten zur Literatur. Frankfurt/M., Suhrkamp, 1981. p. 9-33

ADORNO, Theodor. Notas de literatura I. Trad. Jorge de Almeida. São Paulo: Ed. 34, 2003. Disponível em: $<$ https://onedrive.live.com/?cid=A 43B081EC2D58F79\&id=A43B081EC2D58F79\%21176052\&parId=A 43B081EC2D58F79\%21175980\&o=OneUp>. Acesso em: 06 jan. 2018.

BENJAMIN, Walter. A origem do drama barroco alemão. Trad. Sérgio Paulo Rouanet. São Paulo: Editora Brasiliense, 1984.

BENJAMIN, Walter. História da literatura e ciência da literatura. Trad. Helano Ribeiro. Rio de Janeiro: Editora Sete Letras, 2016.

BENJAMIN, Walter. A crise do romance. Sobre Alexanderplatz, de Döblin. In:__. Magia e técnica arte e política. Ensaios sobre literatura e história da cultura. Obras Escolhidas I. Trad. Sérgio Paulo Rouanet. São Paulo: Editora Brasiliense, 1987. p. 54-60. 
BENJAMIN, Walter. $O$ anjo da história. Belo Horizonte: Editora Autêntica, 2012.

BENJAMIN, Walter. Ursprung des deutschen Trauerspiels. Hamburg: Tredition Classics, 2013.

DIMIER, Louis. L'Évoltion contre l'espirit. Paris: Éditions Spes. 1939.

DÖBLIN, Alfred. O romance histórico e nós. In: KLEINSCHMIDT, Erich (Ed.). Alfred Döblin, Schriften zu Ästhetik, Poetik und Literatur (Escritos sobre estética, poética e literatura). Trad. Alceu João Gregory. Olten und Freiburg im Breisgrau: Walter, 1989. p. 291-316.

GAGNEBIN, Jeanne Marie. História e narração em Walter Benjamin. São Paulo: Editora Perspectiva, 2013.

JACOBS, Jürgen. Wilhelm Meister und seiner Brüder. München: Wilhelm Fink Verlag, 1972.

LIMA, Manuel Ricardo de. Ler com Walter Benjamin. In: BENJAMIN, Walter. História da literatura e ciência da literatura. Trad. Helano Ribeiro. Rio de Janeiro: Editora Sete Letras, 2016. p. 43-61.

OTTE. Georg. Walter Benjamins Umgang mit der Schrift. Pandemonium Germanicum. Revista de Estudos Germânicos, São Paulo, v. 18, n. 25, p. 57-68, 2015. DOI: http://dx.doi.org/10.1590/1982-88373757685.

Recebido em: 3 de outubro de 2018 Aprovado em: 22 de novembro de 2018 